\title{
CONFLICTOS Y JURISDICCIONES: LA CONSTRUCCIÓN DEL NUEVO EDIFICIO E IGLESIA DEL CONVENTO Y COLEGIO DE SAN ELÍAS DE SALAMANCA A FINALES DEL SIGLO XVII
}

Conflicts and jurisdictions: the construction of the new building and church of the convent and college of San Elias de Salamanca at the end of the 17th century

\section{Regina M. ${ }^{a}$ POLO MARTÍN}

Universidad de Salamanca

Correo-e: reg@usal.es

Fecha de recepción: 8 de junio de 2018

Fecha de aceptación: 26 de julio de 2019

RESUMEN: En este trabajo explicamos los enfrentamientos y pleitos ocurridos a fines del siglo XVII en Salamanca con motivo de la construcción de las nuevas dependencias e iglesia del convento y colegio de San Elías de los Carmelitas descalzos en el espacio ocupado por las "casas de Lugo", que años antes habían adquirido con este propósito. Las contiendas se siguieron ante una instancia gubernativa, el consistorio salmantino, y ante dos judiciales, la Audiencia escolástica, ya que al estar incorporado el colegio a la Universidad gozaba de su fuero especial, y el Consejo de Castilla. Los religiosos se enfrentaron al ayuntamiento, a la parroquia de Santo Tomé y a algunos personajes relevantes cuyas casas se vieron afectadas por las obras, destacando el palacio vinculado al Mayorazgo de Suárez de Solís, del que era heredero el conde de Montellano, que tenía gran influencia en la Corte debido a los cargos relevantes que desempeñó.

Palabras clave: pleitos; Carmelitas descalzos; consistorio salmantino; Audiencia escolástica; Consejo de Castilla. 
ABSTRACT: In this work, we explain the clashes that took place at the end of the 17th century in Salamanca with the construction of the new premises and church of the convent and college of San Elías de los Carmelitas barefoot in the space occupied by the «casas de Lugo», which years before they had acquired for this purpose. The contests were followed before an instance gubernativa, the consistory Salamanca, and before two judicial, the scholastic Audience, since when being incorporated the college to the University it enjoyed its special privilege, and the Council of Castile. The religious faced the town hall, the parish of Santo Tomé and some important people whose houses were affected by the works, highlighting the palace linked to the Mayorazgo de Suárez de Solís, of which the Count of Montellano was an heir, who had great influence in the Court because of the very important charges he held.

Keywords: lawsuits; Discalced Carmelites; Consistory of Salamanca; Scholastic Audience; Council of Castile.

\section{PLANTEAMIENTO}

El objetivo de este trabajo es explicar las contiendas y pleitos que surgieron en Salamanca al finalizar el siglo XVII a propósito de la construcción de las nuevas dependencias e iglesia del convento y colegio de San Elías de los Carmelitas descalzos de esa ciudad ${ }^{1}$. La razón que motiva estos apuntes fue el hallazgo en el Archivo Histórico Nacional de unos documentos sobre esta cuestión, en concreto, una consulta dirigida al Consejo de Castilla y los memoriales, informes, etc. que la acompañaban. Este conjunto de papeles suscitó mi curiosidad e interés por la importancia de uno de los contrincantes, un salmantino que años después llegaría a ser presidente del citado Consejo, y porque uno de esos informes estaba firmado por el afamado José de Churriguera.

1. Me remito para los aspectos de historia urbanística sin pretender exhaustividad, con carácter general a Bonet, 1978 y 1991, ambos una recopilación de artículos anteriores, y a Lozano, 20 I I, que dedica a Salamanca las pp. 508-513 y contiene una amplia relación bibliográfica en pp. 605-636. Para la historia urbanística de Salamanca, respecto al siglo XVII Montaner, I987: 9-28, que no hace referencia a este pleito; para el XVIII Rupérez, 1992, que trata en las pp. 85-137 de «Morfología y trazado de la ciudad: calles y plazas», y en las pp. 121-122 hace una mínima referencia a este convento Carmelita, aunque no al litigio estudiado; también contiene una completa relación bibliográfica de carácter general en pp. 302-306, y referida a Salamanca en las pp. 306-308.

Ediciones Universidad de Salamanca / అ@@ Stud. his., H. ${ }^{a}$ mod., 41, n. 2 (2019), pp. 275-302 
El objeto de las disputas eran, como hemos indicado, las obras y actuaciones dirigidas a la ampliación del colegio existente y a la construcción de una nueva iglesia por parte del citado convento de los Carmelitas descalzos. La iglesia, que pese a los enfrentamientos se terminó erigiendo y consagrando en 1703 (Madruga, 2005: 50), fue proyectada por el «arquitecto» carmelita fray Antonio de Jesús María que residía en el convento, siguiendo el modelo de la del Convento de Santa Teresa de Ávila (Madruga, 2005: 51)². En los años en que se planteó esta querella, ni el nombre ni la disposición de la plaza en que se encuentra dicha iglesia eran los mismos de ahora, puesto que en el centro estaba la parroquia de Santo Tomé que daba nombre a la citada plaza. Esta iglesia fue demolida por su estado ruinoso, pasando en 1857 la del convento carmelita a ser parroquia, y la plaza a denominarse de los Bandos dos años después (García, 2015: 438).

En torno a la parroquia de Santo Tomé, delimitando la plaza, se alzaron nobles e importantes edificios pertenecientes a las familias más ilustres de la ciudad. Algunos aún siguen en pie, mientras que otros han desaparecido de este espacio urbano. Precisamente uno de los que se ha perdido prácticamente en su totalidad es el palacio de Solís, que fue centro de las agrias disputas que analizamos. En este palacio, construido a instancias de Alfonso de Solís y terminado en torno a 1475, contrajo matrimonio en 1543 el futuro Felipe II con María de Portugal. En aquel momento pertenecía a María de Solís que estaba casada con el licenciado Diego Ruiz de Lugo. Por esta razón se conocía también como casas de Lugo, denominación que se utilizaba todavía en la documentación de finales del siglo XVII. Estas casas de Lugo se adquirieron por los Carmelitas descalzos en 1678 (López, I997: 170), y era en ellas y en otros edificios adyacentes donde querían construir parte del nuevo convento y la nueva Iglesia.

Por lo que se refiere a los contendientes, por una parte encontramos, como ya sabemos, a los Carmelitas descalzos de Salamanca. Explica Enrique Llamas (2002: 688) los avatares por los que atravesó el proceso fundacional del convento y colegio de San Elías, del que hoy solo se conserva precisamente la iglesia del Carmen, afirmando que, aunque Santa Teresa desde el establecimiento en 1570 de un monasterio de monjas en la ciudad «abrigó el propósito de fundar también un colegio para religiosos», el camino no estuvo exento de dificultades. Después de un primer intento fallido, desde 1577 se complicó aún más su posible creación, ya que los carmelitas del colegio de San Andrés presentaron al obispo escritos desfavorables, pidiéndole que no se concediese la licencia de fundación, aunque con la llegada del obispo Jerónimo Manrique de Lara se produjo un cambio de rumbo, de

2. Sobre las construcciones del Carmelo, Muñoz, 1990, quien en la p. 289 habla de que se sabe poco sobre la construcción del nuevo edificio y la iglesia del convento de San Elías de Salamanca por falta de documentación. 
modo que en noviembre de 1579 la otorgó al padre Juan Jesús Roca (Llamas, 2002: 689). Después de un retrasó de dos años fueron el padre Gracián de la Madre de Dios, a quien se había hecho extensiva la mencionada licencia, y otros religiosos, los que establecieron el convento en 1581 (Llamas, 2002: 690), en concreto en el antiguo hospital de San Lázaro, pasado el puente romano (Santa María, 1644: 800). No obstante, se plantearon desde el inicio problemas de espacio que obligaron a alojar temporalmente a algunos de los religiosos estudiantes dentro de la ciudad. Con esta finalidad alquilaron una casa junto a la parroquia de Santo Tomé, la de Alonso de Monroy, y además recibieron una donación de una contigua perteneciente a Cristóbal Suárez de Solís, aunque dos años después todos los religiosos pasaron a la casa de San Lázaro, ampliada, con huerta y con la iglesia debidamente restaurada (Santa María, 1644: 801).

Afirma E. Llamas (2002: 691-692 y nota 19) que, además de la organización de los estudios en el colegio, la principal preocupación fue conseguir su incorporación a la Universidad de Salamanca, presentando en 1583 y 1584 al claustro del Estudio solicitud para ello, con petición de admisión a todos los actos universitarios. Recibieron respuesta favorable, pero con la restricción de que «no se les concedieron "actos mayores" por estar ya otorgados a otros colegios más antiguos», asistiendo a partir de 1584 los estudiantes a clase.

Poco años después, una crecida del río Tormes en enero de 1597 arrasó prácticamente todas las pertenencias de los religiosos, de manera que la autoridades civiles y eclesiásticas les permitieron construir un nuevo convento dentro del casco urbano (Llamas, 2002: 692). Para solucionar el problema inmediato de su traslado intramuros se buscó una casa en la calle de los Herreros, que, aunque «bien pequeña, obscura i humeda», sirvió para recoger a una docena de religiosos, mientras otros quedaban repartidos por los conventos de la provincia (Santa María, 1644: 802). Las noticias sobre lo que aconteció posteriormente son confusas. Parece que primero vivieron en la casa que compraron a Alonso de Monroy en la que ya habían estado al llegar a la ciudad (Llamas, 2002: 692-693), ubicada sobre la actual plaza de la Libertad con entrada por la calle que hoy se denomina Espoz y Mina. Tras numerosas reformas, se inauguró el colegio y convento en abril de 1597 (Llamas, 2002: 693), eligiéndose como patrón a San Elías. Posteriormente comenzaron a adquirir las casas de alrededor, entre ellas las de Lugo, hasta ocupar la manzana entera, disfrutando de una huerta en el espacio que actualmente es la Plaza de Libertad (Martínez, Pérez y Lahoz, 2008: 76).

Otro de los contendientes, José de Solís, era ya en esta época conde de Montellano y personaje relevante en el entramado político-institucional de la Monarquía hispánica. Nacido en Salamanca en 1643 y fallecido en Madrid en 1713, a lo largo de su vida desempeñó numerosos cargos al servicio de la Corona (Granda, 2013: 314). Además de regidor de Salamanca (Sánchez, 2011:383), durante el reinado de 
Carlos II fue asistente de Sevilla entre 1687 y 1691 (Ortiz de Zúñiga, 1796: 404 y 424), presidente de la Casa de Contratación sevillana de 1693 a 1695, presidente del Consejo de Indias en 1695 y virrey de Cerdeña desde 1696 hasta 1701, ya en el reinado del primer Borbón (Barrios, 1984: 411). En los primeros años de dicho reinado fue presidente del Consejo de Órdenes desde julio de 1702 (Garma y Durán, 1751: 399), culminando este cursus honorum con el nombramiento como gobernador del Consejo de Castilla en noviembre de 1703, puesto que desempeñó hasta el 6 de ese mismo mes de 1705 (Granda, 2013: 314 y 316) . El mismo día de su cese (Barrios, 1984: 411) fue "promovido al Consejo de Estado", en el que permaneció hasta su fallecimiento (Granda, 2013: 316, nota 1279).

En relación con los conflictos y litigios que nos ocupan, al Mayorazgo de Suárez de Solís, del que era poseedora y usufructuaria Gerónima de Solís, hermana del mencionado José (y éste y su hijo sucesores en el mismo), estaba vinculada una casa ubicada en la calle Concejo, que era el palacio en el que se hospedó Felipe II al llegar a Salamanca para contraer matrimonio. Esta casa, contigua al palacio de Solís donde se celebraron los desposorios, se había construido por Cristóbal Suárez (de Acebo), personaje destacado ya que fue contador mayor y tesorero de Carlos I (Madruga, 2005: 30). Este edificio, del cual no se conserva actualmente ningún resto, impedía la comunicación entre las dependencias que los Carmelitas habían ido comprando en esa manzana y, por consiguiente, se vio inmerso en las disputas acaecidas. En estos enfrentamientos, José, ausente de la península, estuvo representado por su mencionada hermana, que en estos años era marquesa viuda de Villaviciosa (Sánchez, 2011: 382).

Igualmente se vieron implicados en estos conflictos otros individuos destacados de la vida y sociedades salmantina y española de la época, alguno de ellos desempeñando, como José de Solís, cargos y oficios influyentes en el ámbito de la Monarquía. La causa fue que sus mansiones también se encontraban situadas en calles adyacentes a las casas del convento de San Elías o al espacio en el que se pretendía construir los nuevos colegio e iglesia. Los iremos citando en las páginas siguientes.

\section{DESARROLLO DE LAS CONTROVERSIAS}

¿Qué sucedió y qué pleitos se siguieron en estos años de fines del siglo XVII y comienzos del XVIII en relación con la ampliación del convento y colegio de San Elías y la construcción de su nueva iglesia? ¿Qué jurisdicciones y tribunales se vieron involucrados?4 De la documentación recogida en el expediente de la consulta del

3. Sobre la actuación de Montellano en estos años véanse Castro, 2004 y Dubet, 2008.

4. Este tipo de pleitos sobre cuestiones urbanísticas en los que intervenían diversas jurisdicciones (regia, escolástica...) no fueron algo extraño en Salamanca, véase por ejemplo el

Ediciones Universidad de Salamanca / అ@@ Stud. his., H. ${ }^{a}$ mod., 41, n. 2 (2019), pp. 275-302 
REGINA M. ${ }^{a}$ POLO MARTÍN

CONFLICTOS Y JURISDICCIONES: LA CONSTRUCCIÓN DEL NUEVO EDIFICIO E IGLESIA

DEL CONVENTO Y COLEGIO DE SAN ELÍAS DE SALAMANCA A FINALES DEL SIGLO XVII

Archivo Histórico Nacional (en los sucesivo AHN) y de la información obtenida en los libros de actas del consistorio salmantino y en el Archivo de la Universidad de Salamanca (de ahora en adelante AUSA) se desprende que era un asunto más intrincado de lo que parece, en el que las instituciones y particulares implicados actuaron ante diferentes instancias gubernativas y judiciales para resolver sus diferencias.

\subsection{El consistorio salmantino}

La primera institución que fue testigo de las pendencias que estudiamos fue el ayuntamiento salmantino, que descansaba en estos años sobre dos pilares fundamentales, ambos de origen bajomedieval, el corregidor y los regidores. En efecto, fueron las reformas de Alfonso XI en la primera mitad del siglo XIV las que trajeron consigo su irrupción en el ámbito del gobierno concejil, y con ellas un creciente intervencionismo de la monarquía en la vida de las ciudades.

No es de extrañar que el ayuntamiento se viera inmerso en estas contiendas, puesto que entre sus atribuciones gubernativas destacan las relacionadas con las cuestiones urbanísticas. ${ }^{5}$. Y por este motivo, con anterioridad a la consulta del Consejo de Castilla de enero de 1698, las actas de la corporación salmantina nos informan con detalle del enfrentamiento entre los Carmelitas descalzos por una parte y la ciudad y diversos particulares e instituciones por otra, en relación con las obras que estaba realizando el colegio de San Elías en las casas de Lugo. Por tanto, fueron cuestiones urbanísticas, cuya resolución correspondía al consistorio, las que desencadenaron la batalla judicial posterior. Veamos qué sucedió.

El hecho inicial que, en parte, años más tarde va a provocar este litigio fue la compra de las casas de Lugo en 1678 por el convento de Carmelitas descalzos con la pretensión de ampliar el espacio de que disponían. Esa venta no fue fácil, tal y como se desprende de la pormenorizada información que sobre la misma nos proporciona un documento, en defensa de los Carmelitas, sobre el pleito que se siguió

seguido en la segunda mitad del siglo XVIII sobre unos edificios de la calle Zamora, en el que, como en el caso que explicamos, se vieron involucrados la Audiencia escolástica salmantina, el Consejo de Castilla y también la Chancillería de Valladolid, en Nieto y Rupérez, 1998: 343-366.

5. Nieto y Rupérez (1998: 351) afirman en relación con la segunda mitad del siglo XVIII que «Salamanca no disponía de una regulación específica para las cuestiones urbanísticas», por lo que previsiblemente tampoco las hubiera en el último cuarto del siglo XVII que es cuando sucedieron estos hechos, por lo que probablemente el ayuntamiento se apoyaría para tomar sus decisiones en las Ordenanzas de Juan de Torija de 1661 relativas a la villa de Madrid -las de Ardemans de 1719 son posteriores al inicio de esta contienda. Véase al respecto, Blasco, 1991, quien dedica la Quinta parte (pp. 732-949) a estudiar «El Tratado de Teodoro Ardemans sobre ordenanzas urbanas (1719)», con referencias asimismo a las de Torija. También Anguita, 1997, que se ocupa de esta normativa en el Capítulo III «La protección del espacio de calle en la ordenanza del Antiguo Régimen», pp. 59-98.

Ediciones Universidad de Salamanca / 요 Stud. his., H. ${ }^{a}$ mod., 41, n. 2 (2019), pp. 275-302 
casi veinte años después, conservado en el AUSA. En este documento, Manifiesto legal... elaborado por el licenciado Marcos Antonio Álvarez Pérez de Argayo ${ }^{6}$, se refleja el deseo del colegio de San Elías de «ensancharse» debido a que el espacio que ocupaba era muy estrecho, lo cual solo era posible adquiriendo las casas de Lugo o la del conde de Montellano, de manera que al negarse este lo intentaron con las primeras, aunque tenían el inconveniente de no ser contiguas al colegio, a diferencia de la de Montellano?.

Tras un intento fallido en 1670, la venta definitiva comenzó con la firma el 11 de noviembre de 1677 de una escritura entre el convento y Pedro Fernández de Velasco, por la que este se obligó a la enajenación, siendo el precio fijado cinco mil ducados y la entrega secreta al citado Pedro de « 15 u y 500 reales de joyas». Correspondía al convento obtener en el plazo de un año la facultad regia para desvincular las casas del Mayorazgo de los Solís, quedando nulo en caso contrario el contrato ${ }^{8}$. Recalcaba el licenciado Álvarez Pérez de Argayo en su Manifiesto que esta información fue notoria para caballeros, regidores, ciudadanos y plebeyos de Salamanca, porque durante seis meses se hicieron por los Carmelitas descalzos públicamente en la ciudad las oportunas diligencias, que, terminadas en 28 de febrero de 1678, fueron remitidas a la Cámara de Castilla para tramitar la facultad ${ }^{9}$. Este organismo determinó que entre esas diligencias faltaba la tasación por peritos del valor de las casas, de la cuantía de lo que rentaban y del importe de las reparaciones precisas, puesto que se aseguraba que estaban mal conservadas, por lo que por cédula de 28 de marzo se ordenó al corregidor salmantino que nombrase a tal efecto «Alarifes, y Maestros peritos en el arte» ${ }^{10}$.

Un hecho luctuoso va interrumpir este proceso, ya que, recibida la cédula por el lugarteniente del corregidor, llegó a la ciudad la noticia del fallecimiento del vendedor, Pedro Fernández de Velasco, quien había firmado el contrato con el convento el 15 de marzo de 1678. Por ello se ordenó informar de las circunstancias de la enajenación en marcha a su hijo y sucesor en el Mayorazgo, José Fernández de Velasco, en concreto, a su madre y curadora, Francisca Velázquez, pues era menor

6. Manifiesto legal y verdadera relación, por la defensa del Colegio de San Elias, Carmelitas descalços desta ciudad de Salamanca, encorporado en su insigne Universidad. En la causa que injusta, y temerariamente le ha movido D. Pedro Fernández de Velasco, hijo mayor de familias de D. Joseph Fernández de Velasco, Marqués de Cilleruelo, vecino de Medina del campo, Sobre la reivindicación de las casas que llaman de Lugo, del Mayorazgo de los Solises, y otras accesorias, que están a la Colación de Santo Thomé, Parroquial desta dicha Ciudad, cuyo derecho y pretensión coadiuva la Justicia, y Regimiento de esta dicha Ciudad, contradiciendo a dicho Colegio el uso, y aprovechamiento de dichas casas (AUSA, PU, 86, 14, fols. 1-36).

7. Manifiesto..., fol. 3.

8. Manifiesto..., fol. 4.

9. Manifiesto..., fols. 4-5.

10. Manifiesto..., fols. 5-6.

Ediciones Universidad de Salamanca / అ@@ Stud. his., H. ${ }^{a}$ mod., 41, n. 2 (2019), pp. 275-302 
REGINA M. ${ }^{a}$ POLO MARTÍN

CONFLICTOS Y JURISDICCIONES: LA CONSTRUCCIÓN DEL NUEVO EDIFICIO E IGLESIA

DEL CONVENTO Y COLEGIO DE SAN ELÍAS DE SALAMANCA A FINALES DEL SIGLO XVII

de edad. La citada Francisca aceptó continuar con el contrato, pero endureciendo sus condiciones ${ }^{11}$. A pesar de ser muy gravosas, el padre fray Juan Jesús de María, entonces prior del Convento de Medina que luego fue rector del colegio de San Elías, por la estrechez del colegio y por no perder lo gastado en conseguir la facultad, se allanó a ellas ${ }^{12}$.

Una vez resueltas estas cuestiones, continuaron donde se habían interrumpido los trámites para la conclusión de la venta. Así, se nombró por el teniente de corregidor como alarifes tasadores a Juan de Segovia y a Manuel Pino, maestros de obras de la catedral y Monterrey, respectivamente, quienes declararon que el valor de las casas era de cinco mil ducados y que los reparos valdrían ocho mil reales. Por su parte el Administrador de las casas informó de que rentaban cien ducados ${ }^{13}$. Toda esta información se remitió a la Cámara de Castilla el 18 de mayo de 1678, concediéndose por cédula de 19 de junio facultad para desvincular las casas del Mayorazgo y para que se pudiesen enajenar, de manera que, después de depositar el colegio los cinco mil ducados, se celebró la venta el 31 de julio, tomando el convento pública y pacífica posesión de las casas de Lugo sin ninguna contradicción ${ }^{14}$.

Después de esta adquisición, la primera noticia que tenemos sobre el conflicto que nos ocupa aparece en las actas de la sesión ordinaria del consistorio salmantino de 8 de agosto de 1696, por tanto, casi veinte años más tarde. En este momento el corregidor de la ciudad era Martín Basurto de Sepúlveda. En la citada reunión se vio una petición dirigida al ayuntamiento por el rector del colegio de San Elías, el aludido fray Juan de Jesús María. En ella, en primer lugar, se dejaba claro que en la facultad regia por la que se desvincularon las casas de Lugo se permitía enajenarlas para incorporarlas al colegio sin que nadie pudiera impedirlo ${ }^{15}$. Y en segundo lugar, se solicitaba se le concediera licencia para la construcción de un pasadizo por debajo de la calle Cabrera que uniese el antiguo convento y colegio a esas casas, con el compromiso de costear la edificación de las bóvedas necesarias para que la obra fuera segura y de no perjudicar ni al espacio público ni a los moradores particulares de

11. En concreto determinó que "correría con dicho contrato, con tal que se la diesen $2 u$ ducados de joya; y con tal, que los $5 \mathrm{u}$ ducados, que se avían de depositar en el Depositario General, o en quien la Justicia señalase, avian de estar a riesgo de el dicho Colegio", añadiendo que desde el día de la venta y toma de posesión por el colegio se le pagasen réditos «a razón de 20u. el millar», debiendo obtener el colegio a su costa facultad para tomar los cinco mil ducados a censo «sacarlos del riesgo en que podían estar por la baja, que entonces se tenía de moneda» para que pudiera «tener instrumento para poder pedir al Colegio» (Manifiesto..., fols. 6-7).

12. Manifiesto..., fol. 7.

13. Manifiesto..., fol. 9.

14. Manifiesto..., fols. 9-10.

15. Libro de Actas del Ayuntamiento (en lo sucesivo LAA) de 1696, fols. 97r-97v, en Archivo Histórico Municipal de Salamanca (en adelante AHMS), Registro de Actas de Sesiones (en lo sucesivo RAS) 1996/81. 
esa calle, ofreciéndose para ello a hacer las «escript $u^{\text {ras }}$ y obligaciones» necesarias ${ }^{16}$. Véase para facilitar la comprensión del asunto la Lámina 1 que contiene el plano de situación incluido en la documentación de la Consulta dirigida por Consejo de Castilla al monarca. En él, creo que por error, aparece la calle Cabrera como de la Cuesta del Carmen. En cualquier caso era la que unía la calle de Peripacho (actual plaza de la Libertad) con la plazuela de Santo Tomé (hoy en día plaza de los Bandos). Se observa claramente como el colegio y convento antiguos (figuran como «fábrica del combento») están separados de las casas de Lugo, que era donde se quería edificar el colegio e iglesia nuevos, por la casa y jardín del conde de Montellano.

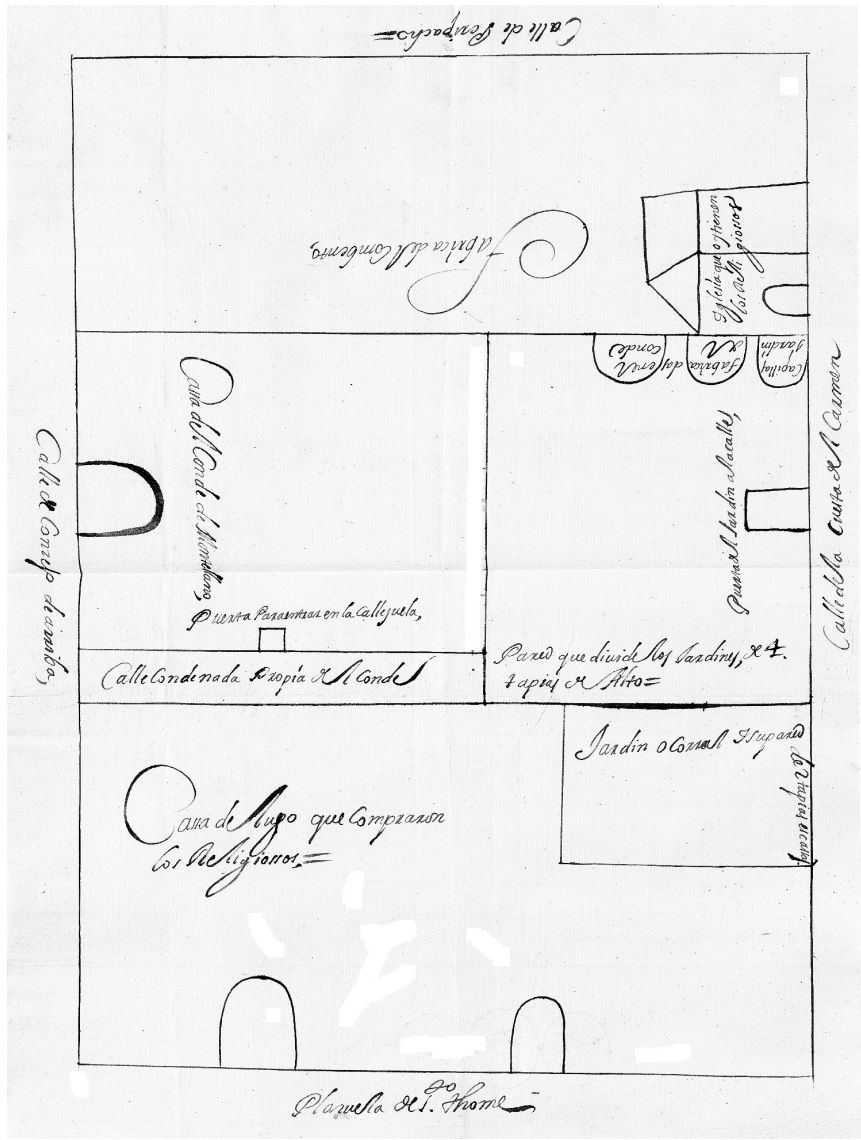

1. Plano de situación (AHN, Legajo 7211)

16. LAA de 1696, fol. 97v, en AHMS, RAS 1996/81.

Ediciones Universidad de Salamanca / అ@@ Stud. his., H. ${ }^{a}$ mod., 41, n. 2 (2019), pp. 275-302 
REGINA M. ${ }^{a}$ POLO MARTÍN

CONFLICTOS Y JURISDICCIONES: LA CONSTRUCCIÓN DEL NUEVO EDIFICIO E IGLESIA

DEL CONVENTO Y COLEGIO DE SAN ELÍAS DE SALAMANCA A FINALES DEL SIGLO XVII

Esta petición suscitó la oposición inmediata de diferentes instituciones y particulares que se consideraban perjudicados por la posible construcción de ese pasadizo. En concreto, en el mismo consistorio de 8 de agosto se vio la «contradizion» que oponía Felipe de Rueda en nombre de todos los beneficiados de la parroquia de Santo Tomé, que se basaba en perjuicios económicos ${ }^{17}$, y en el del día 17 del mismo mes otras cuatro por parte de los individuos propietarios de casas o palacios tocantes a la calle Cabrera que se quería minar por los Carmelitas para hacer el pasadizo. Estas cuatro contradicciones están transcritas en las actas de la sesión de 22 de agosto. Todos los afectados reclamaban al ayuntamiento que se denegase al colegio de San Elías la concesión de la licencia para la excavación del pasadizo. Veamos las razones por las que oponían a dicha construcción en sus escritos.

En primer lugar la de Gerónima Solís, que, como sabemos, se presentaba como usufructuaria del Mayorazgo de Suárez de Solís, y actuaba en su nombre y en el de su hermano José de Solís y de su sobrino Alonso Suárez de Solís, hijo del anterior, legítimos sucesores en ese Mayorazgo. Esta contradicción se fundamentaba en los quebrantos arquitectónicos y de salubridad que la construcción del pasadizo supondría para su casa ${ }^{18}$, haciendo hincapié sobre todo en que quedaría encajonada entre los edificios de los Carmelitas, privada de «aires», vistas y luces por lo que se verían precisados a salir de ella, a «desamparar» esta casa ${ }^{19}$.

La segunda contradicción la presentó José Ordóñez Flórez Godínez, regidor de la ciudad, como poderhabiente de su hermano Francisco, que era regidor perpetuo de Málaga y titular del mayorazgo de los Flórez. También se basada en menoscabos de carácter arquitectónico, el perjuicio que al excavarse el pasadizo se ocasionaría a los cimientos de sus casas ${ }^{20}$, advirtiendo además que se le privaría de una servidumbre de un conducto que distaba setenta y seis pies del colegio ${ }^{21}$.

17. Se exponía como argumento el daño que la incorporación de esas casas provocaba a la iglesia «por quitar ...el ingreso de diezmos como de personas que asistan en sus mayordomías y demás derechos parroquiales» (LAA de 1696, fols. 98v-99r, en AHMS, RAS 1996/81).

18. Explicaba que «la Casa prinzip $a^{1}$ de dicho mi mayorazgo sale a dicha Calle de Cabrera y en ella se estiende por non poco trecho por lo que rezivirán sus paredes el gravísimo perjuizio de ser mobidos nezesariamen $n^{\text {te }}$ sus Cimientos, para fundar las bóvedas con la seguridad que se promete», añadiendo que «no dando lugar a otra cosa lo estrecho de dicha Calle rezivirá el perjuicio de una servidumbre perpetua de no poder arojar en ella sin contradizión un jarro de agua...» (LAA de 1696, fol. 106r, en AHMS, RAS 1996/81).

19. Decía textualmente que quedaría «tan acordonada por todos lados que no pudiendo sus habitaciones respirar ni por el lado de mediodía por donde está unida con dicho Colegio ni por el lado del norte a donde nuebamente se pretenda fundar otro ni por el poniente que es por donde se quiere ahora travajar la mina, sea y an de salir por la salud pues le faltan los ayres, por la comodidad pues sele quitan las Vistas y las luzes, por el decoro pues la cercan los Carmelitas descalços cuya sannísima y solitaria profesión está muy desunida y desviada de lo seglar» (LAA de 1696, fols. 106r-106v, en AHMS, RAS 1996/81).

20. LAA de 1696, fol. 107v, en AHMS, RAS 1996/81.

21. LAA de 1696, fol. 107v, en AHMS, RAS 1996/81.

Ediciones Universidad de Salamanca / @®@@ Stud. his., H. ${ }^{a}$ mod., 41, n. 2 (2019), pp. 275-302 
Felipe Rodríguez de Quintas, en nombre y con poder de José Fernández de Velasco Bobadilla, poseedor y sucesor del Mayorazgo de Solís al que habían estado vinculadas las casas de Lugo, exponía dos cuestiones diferentes en su contradicción. En primer lugar, se indicaba que hace años, siendo su representado menor de edad, se procedió a la venta de tales casas «con engaño y con relazion siniestra» por lo que se había iniciado pleito contra el colegio de Carmelitas para rescindir esa enajenación alegando la lesión «enormísima» que tal venta le había provocado en sus bienes, ya que actualmente había comprador interesado que le abonaría diez mil ducados, a pesar de lo cual José Fernández de Velasco, «atendiendo al lustre de dicha Casa y su antigüedad», la quería conservar ${ }^{22}$. Por tanto, se hacía mención al pleito que explicaremos a continuación sobre la legalidad de la enajenación de las casas de Lugo y acerca de la posible lesión causada. Y en segundo lugar, añadía que había conocido la pretensión del colegio de realizar el pasadizo, pidiendo que se denegase la licencia porque era en detrimento de las citadas casas ${ }^{23}$.

La última contradicción fue la que presentó el citado Rodríguez de Quintas en nombre y con poder de Enrique Enríquez de Sevilla, capitular del consistorio salmantino, como administrador de los Mayorazgos de su padre Pedro Luis Enríquez de Sevilla, caballero de la Orden de Calatrava, conde de Canillas de los Torneros, y en estos momentos presidente de la Audiencia de Panamá. Se fundamentaba también en los daños que para la habitabilidad y salubridad de sus casas provocaría el minar el suelo de la calle Cabrera ${ }^{24}$. Además, advertía de los posibles pleitos a que se verían avocados sobre la seguridad de los cimientos y acerca de la exigencia de que se le reconociese una servidumbre de verter aguas desde las ventanas sobre las bóvedas del pasadizo ${ }^{25}$, añadiendo como otro argumento en contra que con el paso del tiempo le podrían exigir la colocación de canalones de hierro en los tejados para recoger las aguas a fin de que no cayesen sobre el pasadizo y calle ${ }^{26}$. Los dos primeros escritos de oposición y este último recogían la advertencia de que en el caso de que se suscitase pleito se obligaban a hacer frente a los gastos que se ocasionasen ${ }^{27}$.

En el citado consistorio de 22 de agosto de 1696 en el que se iba a tomar la decisión acerca de la licencia requerida, además de los cuatro escritos anteriores, se leyeron una nueva solicitud del rector de los Carmelitas descalzos en la que pedía al

22. LAA de 1696, fol. 108v, en AHMS, RAS 1996/81.

23. LAA de 1696, fol. 109r, en AHMS, RAS 1996/81.

24. Explicaba que para realizar el pasadizo que pretendía el colegio de Carmelitas «es preciso que lebanten las paredes de la guerta de dicha casa», lo cual causaría gran perjuicio, y también "por quitarle por el estrecho de la calle el sol del oriente y quedará aora muy oscura» (LAA de 1696, fol. 109v, en AHMS, RAS 1996/81).

25. LAA de 1696, fol. 110r, en AHMS, RAS 1996/81.

26. LAA de 1696, fol. 110r, en AHMS, RAS 1996/81.

27. LAA de 1696, fols. 106v-107r, 108r y 110v, en AHMS, RAS 1996/81.

Ediciones Universidad de Salamanca / అ@@ Stud. his., H. ${ }^{a}$ mod., 41, n. 2 (2019), pp. 275-302 
ayuntamiento testimonio de estas contradicciones, anunciando la intención de acudir a juicio para resolver estas diferencias antes de que la corporación municipal decidiese sobre el permiso para el pasadizo ${ }^{28}$, y los pareceres emitidos por dos abogados, los dos catedráticos de Prima de la Universidad de Salamanca ${ }^{29}$, sobre si la petición de los Carmelitas de hacer el pasadizo era materia de gracia o de gobierno, tal y como se había requerido en la reunión de 17 de agosto. El parecer de los dos se inclinaba a considerarla de gracia ${ }^{30}$, y del mismo modo se estimó por el consistorio después de la votación correspondiente ${ }^{31}$. Fijado este punto a continuación se pasó a votar la petición de la licencia para hacer el pasadizo, resultando denegada ${ }^{32}$. A pesar de ello los conflictos no cesaron, puesto que pocos meses después en el consistorio del 18 de octubre de 1696 se notificó a la corporación que los Carmelitas estaban demoliendo «las casas conjuntas alas de Lugo» a pesar de las contradicciones presentadas por los interesados, acordándose, tras la pertinente votación, que la ciudad acudiese a pleito defendiendo su derecho a que no se derribasen esas casas y a que lo demolido se tornara al estado anterior ${ }^{33}$.

\subsection{La Audiencia escolástica salmantina}

Benjamín González Alonso (1998: 382) afirma que la justicia en el Antiguo Régimen «se adaptó fielmente a los fundamentos de la sociedad establecida, basada en el privilegio y en la que coexistían tantos regímenes jurídicos como sectores sociales diferenciados», de ahí la existencia de numerosas jurisdicciones especiales, entre ellas la universitaria. Paz Alonso Romero (2004: 163) nos explica que la Universidad de Salamanca gozó de fuero especial a lo largo de los siglos como consecuencia de los privilegios otorgados por reyes y papas, y añade que fueron los maestrescuelas de la catedral salmantina los que ejercieron esa jurisdicción desde el siglo XIII hasta

28. LAA de 1696, fols. 102v-103r, en AHMS, RAS 1996/81.

29. LAA de 1702, fol. 26v, en AHMS, RAS 1997/87.

30. El doctor Lorenzo González afirmaba con rotundidad que esa pretensión «no es acto necesario y preziso...en que para su resoluzion baste la mayor parte y es solo voluntario, y lo boluntario que este negozio tiene es más de grazia que de gobierno» (LAA de 1696, fol. 111r, en AHMS, RAS 1996/81). Por su parte, el doctor Andrés García de Samaniego determinaba que «aunque no fueran (los vecinos interesados) de tan conoçida calidad como son se les debía atender para que en ningún acontecimiento se les pudiese seguir el daño que themen y con perjuiçio de terçero ni aun el prínzipe acostumbra jamás a conceder nada de grazia» (LAA de 1696, fol. 111v, en AHMS, RAS 1996/81).

31. LAA de 1696, fol. 113r, en AHMS, RAS 1996/81.

32. LAA de 1696, fol. 113r, en AHMS, RAS 1996/81. Hay que hacer constar que en la documentación manejada no aparece reflejado el motivo urbanístico de la denegación por parte del consistorio salmantino de la licencia para la construcción del pasadizo.

33. LAA de 1696, fol. 149r, en AHMS, RAS 1996/81.

Ediciones Universidad de Salamanca / @®@@ Stud. his., H. ${ }^{a}$ mod., 41, n. 2 (2019), pp. 275-302 
el XIX ${ }^{34}$, aunque su vicario o lugarteniente, el juez del Estudio, «era quien habitualmente se encargaba de administrar justicia y ejercer el poder disciplinario en su nombre» (Alonso, 1997: 275).

¿Quiénes eran los beneficiarios del fuero? Según P. Alonso (1997: 252 y 264), además de la Universidad persona ficta y los studiosi, se añadieron con el tiempo otras personas o instituciones, y entre ellos se incluyeron los colegios, conventos y monasterios incorporados a la Universidad. Obviamente en esta situación se encontraba el colegio de San Elías, por lo que la segunda instancia involucrada en este enfrentamiento fue la Audiencia escolástica, órgano ya de carácter propiamente jurisdiccional. En cuanto al proceso escolástico, la citada Alonso Romero (1998: 187) afirma que se caracteriza por un estilo procesal «rápido ${ }^{35}$, sencillo y alejado de formalidades ordinarias», aunque no siempre se consiguió, sobre todo la rapidez ${ }^{36}$. Explica que el proceso civil se centraba en la petición y la prueba, distinguiendo dos fases: la primera tenía como finalidad la fijación de posturas y la segunda la práctica de pruebas dejando el juicio visto para sentencia (Alonso, 1997: 299).

El maestrescuela de Salamanca entre 1682 y 1701, por tanto en el momento en que se desarrolló este pleito, era Diego de Sierra y Valcarce (Alonso, 1997: 330). Ignoramos los pormenores procesales de la causa seguida, al no conocer las actas del pleito, pero en el Manifiesto del licenciado Álvarez Pérez de Argayo de 15 de diciembre de 1696 se refleja la defensa del colegio de Carmelitas en la causa que promovió contra él Pedro Fernández de Velasco, hijo mayor de José Fernández de Velasco, sobre las casas de Lugo, actuando como coadyuvantes la Justicia y Regimiento de la ciudad ${ }^{37}$. Según datos proporcionados por este documento la demanda se interpuso el 17 de octubre de 1696 por el citado Pedro Fernández de Velasco, nacido en 1686 y en situación al tener solo 10 años de «hijo de familias», persuadido por dos de los dueños de las casas afectadas, que se obligaron a pagarle los gastos a cambio de que iniciase el litigio ${ }^{38}$. De acuerdo con la celeridad de este tipo de procesos ante el maestrescuela, en diciembre estaba ya en curso, sin que en este momento estuviese todavía la causa recibida a prueba ${ }^{39}$.

De la información recogida en este Manifiesto se deduce que lo que se dilucidaba en este pleito era la venta de las casas de Lugo. En concreto, se decía que la

34. Un detallado estudio sobre esta materia se contiene en Alonso, 1997.

35. Señala que los plazos eran muy cortos, habitualmente de seis días (Alonso, 1997: 297).

36. Este proceso aparente sencillo se podía alargar «con los artículos de excepciones (en la primera fase), la realización de diligencias fuera de Salamanca o el planteamiento de cuestiones incidentales sobre las que debía pronunciarse el juez antes de seguir adelante» (Alonso, 1997: 299).

37. AUSA, PU, 86, 14, fol. 1.

38. AUSA, PU, 86, 14, fol. 23.

39. AUSA, PU, 86, 14, fol. 2.

Ediciones Universidad de Salamanca / 요 Stud. his., H. ${ }^{a}$ mod., 41, n. 2 (2019), pp. 275-302 
disputa del litigio se reducía a tres dificultades: determinar si la enajenación fue o no legítima y legal, verificar si intervino la lesión que se alegaba y dirimir si Pedro Fernández de Velasco y la Justicia y Regimiento de la ciudad eran partes legítimas para intentar la causa ${ }^{40}$, siendo, por consiguiente, estas las materias abordadas en el discurso del licenciado Álvarez Pérez de Argayo, no olvidemos en defensa de los Carmelitas descalzos.

Respeto a la primera cuestión, la determinación de si la venta de las casas de Lugo fue o no legítima y legal, explicaba que contra esa enajenación la parte contraria a los Carmelitas invocaba los vicios de «orrepción y subrepción», al no haberse comunicado al rey que esas casas eran las principales del Mayorazgo de Solís, que no tenía el citado Mayorazgo de renta seis mil reales y que en la ciudad de Salamanca no poseía «más que un juro de renta de quinientos», por lo que se estimaba nula la venta ${ }^{41}$. A continuación probaba Álvarez Pérez de Argayo que no existieron esos vicios, ya que, en primer lugar, en la cédula real que se despachó para que se realizasen las diligencias debidas se ordenó expresamente al vendedor Pedro Fernández de Velasco, abuelo del demandante, que presentase cuáles eran los bienes vinculados a sus Mayorazgos, como así hizo, por lo que el monarca supo en todo momento la cualidad de las casas de Lugo ${ }^{42}$. En segundo lugar, defendía que el tener más o menos renta en la ciudad que el juro mencionado no pudo ser la «causa impulsiva, ni final» para que el príncipe (léase a partir de ahora monarca) concediese o denegase la licencia para la venta, por «ser más superiores, y eficaces las que se expresaron» por el convento y por el vendedor ${ }^{43}$. Por todo ello sostenía que no se podía alegar ningún vicio estimable, pues el comprador era hábil con licencia de su obispo, el vendedor y la cosa vendida libres de la prohibición de enajenación por la facultad concedida por el monarca, y al ser el precio cierto y determinado «quedó perfecta totalmente la dicha enagenación con el depósito de dicho precio, que fue físico, y real» ${ }^{44}$.

La parte del Manifiesto que trataba de la segunda dificultad, referida a si medió la lesión que se argüía por el demandante por la que pedía rescindir la venta, es la más extensa de este documento. En primer lugar, para excluir que hubo esa «lesión

40. AUSA, PU, 86, 14, fol. 10.

41. AUSA, PU, 86, 14, fol. 12.

42. AUSA, PU, 86, 14, fol. 13.

43. Las del comprador: «la suma estrechez de su abitación, la corta capacidad de la iglesia, sin capillas al lado de la Epístola, y sin hermitas para los exercicios de virtud que se requieren por estatuto de dicha orden», y las del vendedor: «la ruyna de dichas casas, y que con todo lo que rentavan no podían repararse, y que en el estado en que se hallavan no era utilidad para los posseedores de dicho mayorazgo, sino de mucha costa, y cuydado» (AUSA, PU, 86, 14, fol. 13).

44. AUSA, PU, 86, 14, fols. 14-15.

Ediciones Universidad de Salamanca / 요 Stud. his., H. ${ }^{a}$ mod., 41, n. 2 (2019), pp. 275-302 
enormísima», probaba Álvarez Pérez de Argayo que no intervino dolo en la enajenación por parte ni del comprador ni del vendedor ${ }^{45}$. En segundo lugar, para reconocer si se produjo o no lesión afirmaba que se debían considerar el precio y valor de las casas en el momento del contrato de venta, afirmando que los mismos estaban avalados por muchos testigos exentos de sospecha, y que incluso se hizo esa probanza con citación del entonces sucesor, José de Velasco, a quien por menor de edad se le nombró curador adlitem, judicialmente, que fue el que se citó para el examen de los testigos ${ }^{46}$. Además, explicaba que no hubo lesión en la venta de las casas porque «el precio, y valor físico de ellas, está reducido a la regla de los intereses que valen en arriendo, juntando lo que importa en el espacio de veinte años», en concreto, cien ducados de renta cada año por veinte años daban dos mil ducados, por lo que habiendo pagado el colegio más de ocho mil no podía existir la lesión «enormísima» que se invocaba ${ }^{47}$.

A mayor abundamiento, indicaba que, aparte del precio, los Carmelitas abonaron otros gastos en utilidad del Mayorazgo ${ }^{48}$, teniendo que añadir dos mil ducados de joyas que recibió la curadora Francisca (abuela del demandante), habiendo, por tanto, desembolsado el convento más de doce mil ducados, por lo que estima que la lesión «enormísima» se le produjo al colegio y no al Mayorazgo y sus sucesores ${ }^{49}$. Además, la tasación de los peritos convino en el precio de cinco mil ducados que pagaron los Carmelitas, que excedía del valor regulado por los arriendos, que era de dos mil ${ }^{50}$, de donde se probaba una vez más que no hubo lesión para el vendedor. Y exponía el licenciado Álvarez Pérez de Argayo un último argumento: que si de verdad las casas valieran los veinte mil ducados que se alegaban, habiendo sido la venta $\tan$ notoria y tan dilatada en el tiempo, sin duda habría habido personas que hubieran pagado más que el colegio de Carmelitas ${ }^{51}$. Por todo ello, concluye, el rey consideró legítimo el precio, otorgando permiso y facultad para la enajenación ${ }^{52}$.

45. Respecto al comprador señalaba que «se debe excluir toda presumpcióm, y mala sospecha, por ser religiosos; y de una religión tan abstera, y penitente», y en cuanto al vendedor "por ser un caballero ladino, y sagaz, y sumamente cuidadoso de sus conveniencias») (AUSA, PU, 86, 14, fol. 16).

46. AUSA, PU, 86, 14, fol. 17.

47. AUSA, PU, 86, 14, fol. 18.

48. En concreto, los desembolsos necesarios para obtener la facultad regia que permitiera la compra de las casas; los gastos «de otra facultad que ganó dicho colegio para subrogar un censo del Señor Conde de Monterrey como lo confiesa el padre de la parte contraria»; y «el coste de ciento, y alcabala» (AUSA, PU, 86, 14, fol. 20).

49. AUSA, PU, 86, 14, fol. 20.

50. AUSA, PU, 86, 14, fols. 20-21.

51. AUSA, PU, 86, 14, fol. 22.

52. AUSA, PU, 86, 14, fol. 23. 
La tercera cuestión acometida se refería a la determinación de si Pedro Fernández de Velasco y la Justicia y Regimiento salmantinos eran parte legítima en esta causa.

Respecto al primero citado, nieto del Pedro que principió la venta definitiva en noviembre de 1677 y que falleció durante su tramitación, el autor del Manifiesto se detiene primero a analizar la controversia relativa a la necesidad o no de citar a los inmediatos sucesores para que el monarca concediera al poseedor de un mayorazgo facultad para enajenar algún bien vinculado ${ }^{53}$. Partiendo de la idea de que sí es necesario, el demandante quedaba excluido como parte puesto que en vida de su abuelo se citó a su padre como inmediato sucesor, y tras la muerte del primero al entonces sucesor su tío Esteban Fernández, hermano de su padre, quienes con su consentimiento expreso imposibilitaban toda opción de interponer demanda, por lo que el actual Pedro, según el licenciado Pérez de Argayo, estaba litigando «sin acción, y derecho, por cuya causa debe ser repelido del juicio» ${ }^{54}$. En segundo lugar, se reafirmaba en que estaba excluido de este juicio porque tenía contra sí la autoridad de cosa juzgada ${ }^{55}$.

En relación con la Justicia y Regimiento de Salamanca indicaba Álvarez Pérez de Argayo que su único argumento en contra de la venta era que la incorporación de las casas de Lugo al colegio Carmelita le restaría esplendor y utilidad pública a la ciudad, agravado el mal por el hecho de ser las casas donde se celebraron las bodas de Felipe II, ante lo que afirmaba que, siendo tan grave la necesidad del citado colegio, no se le podía privar ni impedir el uso de las casas compradas para ese fin ${ }^{56}$. Añadía, además, que los argumentos de la corporación no eran apreciables, pues si se pusieran las casas en el estado ruinoso en que estaban cuando se compraron, la ciudad debería adecentarlas, estimando que esa reparación se haría mejor por los Carmelita ${ }^{57}$; es más, si hubiera querido conservarlas para hospedar a otro príncipe «devió salir al tanto en tiempo conveniente» ${ }^{58}$. Tampoco valía el afirmar que se perjudicaba a la parroquia de Santo Tomé, pues en tal caso no habría fundaciones religiosas en la ciudad sino solo en despoblados, y era claro que esto no sucedía en Salamanca, por lo que era indudable que tampoco la ciudad era parte legítima en este litigo ${ }^{59}$.

Finalmente, en este Manifiesto se añadía por el licenciado Álvarez Pérez de Argayo una cuarta cuestión para los supuestos de que el actor Pedro Fernández de Velasco fuese declarado parte legítima en este juicio, «que no puede ser»; de que se

53. AUSA, PU, 86, 14, fol. 25.

54. AUSA, PU, 86, 14, fols. 25-26.

55. AUSA, PU, 86, 14, fol. 27.

56. AUSA, PU, 86, 14, fol. 30.

57. AUSA, PU, 86, 14, fols. 31-32.

58. AUSA, PU, 86, 14, fol. 32.

59. AUSA, PU, 86, 14, fol. 33.

Ediciones Universidad de Salamanca / అ@@ Stud. his., H. ${ }^{a}$ mod., 41, n. 2 (2019), pp. 275-302 
declarara la lesión, «que es imposible»; y de que el colegio se allanase a la restitución de las casas con sus rentas. En este caso la parte contraria, don Pedro, estaría obligado a restituir a los religiosos los cinco mil ducados abonados con doscientos cincuenta de réditos cada año desde el depósito, y también a pagar y satisfacer las mejoras y reparos hechos ${ }^{60}$, pero se preguntaba de dónde iba a obtener esa cuantía estando sujeto aún a la patria potestad paterna, afirmando que su padre diría que no litigaba y tampoco los «movedores» ocultos de este pleito, que alegarían estar solo obligados a pagarle a Pedro las costas ${ }^{61}$. Recordemos que estos «movedores», según el citado Álvarez Pérez de Argayo, eran Enrique Enríquez y Cristóbal de Solís.

Apenas sabemos más de este litigio, y lo que conocemos se debe a la información contenida en el Memorial enviado al monarca por el convento de Carmelitas descalzos, que se incluye en el expediente de la consulta del AHN. En él se hablaba de un litigio ante el maestrescuela, que creemos es al que nos venimos refiriendo, aunque el colegio de San Elías solo aludía en las noticias que transmitía al rey a las contradicciones presentadas por la ciudad y por la parroquia de Santo Tomé, sin hacer ninguna mención a las disputas sobre la legalidad de la venta de las casas de Lugo ni a la posible lesión causada con ella, lo cual no sorprende porque al convento no le interesaba dar visibilidad a esta cuestión y que esa enajenación se pusiera en entredicho.

En concreto, se explicaba en dicho Memorial que el pleito se recibió a prueba y que temerosa Gerónima de Solís de que la sentencia no le fuera favorable «salió aziendo contradiczión descubiertamente ante el mismo Juez Maestre Scuela», solicitando se le diese traslado de los autos para presentarlos ante la instancia que estimase conveniente ${ }^{62}$, pero el maestrescuela dictó sentencia favorable al colegio, desestimando las peticiones y denegando la copia de los autos requerida por la marquesa de Villaviciosa, indicándole que solicitase ante él lo que estimara conveniente $^{63}$. En definitiva, apuntaba ya el colegio la pretensión de doña Gerónima de acudir a otra jurisdicción diferente a la del maestrescuela salmantino.

\subsection{El Consejo de Castilla}

Estando así la situación se produjo un paso más en este enfrentamiento, por el que se vio inmiscuida una nueva instancia jurisdiccional, el Consejo de Castilla, tal y como se deduce del expediente de la consulta manejada.

60. AUSA, PU, 86, 14, fol. 33 .

61. AUSA, PU, 86, 14, fol. 35 .

62. AHN, Consejos, Legajo 7211.

63. AHN, Consejos, Legajo 7211.

Ediciones Universidad de Salamanca / 요 Stud. his., H. ${ }^{a}$ mod., 41, n. 2 (2019), pp. 275-302 
REGINA M. ${ }^{a}$ POLO MARTÍN

CONFLICTOS Y JURISDICCIONES: LA CONSTRUCCIÓN DEL NUEVO EDIFICIO E IGLESIA

DEL CONVENTO Y COLEGIO DE SAN ELÍAS DE SALAMANCA A FINALES DEL SIGLO XVII

El Consejo de Castilla era a finales del siglo XVII uno de los catorce que integraban la polisidonia hispánica. Este Sínodo, institucionalizado por Juan I en las Cortes de Valladolid de 1385, mantuvo su vigencia hasta 1808, con un postrero resurgimiento durante el reinado de Fernando VII. En los años en que acaecieron estas discrepancias se regía por las Ordenanzas de 1608, y actuaba dividido en cuatro salas, una de Gobierno y tres de justicia, las de Mil y Quinientas, Justicia y Provincia, aunque desde 1627 también funcionaba de manera oficiosa una segunda sala de Gobierno.

Este Consejo tenía atribuidas importantes funciones gubernativas y, además, desde las Ordenanzas de Madrid de 1459 facultades jurisdiccionales (Dios, 1982: 121-12) que lo convirtieron en «el tribunal superior del Reino» (Barrios, 2015: 497). En todo caso, durante el reinado de Isabel y Fernando, tal y como afirma S. de Dios (1982: 179-180), se produjo un importante desarrollo de este organismo debido al aumento de su actividad, incluyendo dentro de sus innumerables atribuciones la de aconsejar al monarca en los negocios sometidos a su parecer, responder las consultas planteadas por todos los organismos de justicia y gobierno castellanos, y «en nombre del rey, veía y resolvía - con o sin consulta real- todas las peticiones que le presentasen los concejos, universidades y particulares, tanto en asuntos de gobierno como de justicia, etc.». Así, en cuanto a su actuación, según el mencionado S. de Dios (1986: XXIII y XXV), junto con las vías de expediente - utilizada para la resolución de los negocios gubernativos -, y de cámara o merced - para la de los asuntos de gracia, merced y patronato real-, se consolidó la vía de proceso, en la que, en contra de lo establecido en las Ordenanzas de 1459 y en las de Toledo de 1480 de articular un proceso breve, se inclinó «a conocer de acuerdo a las formas y solemnidades del proceso ordinario» caracterizado por su lentitud.

El primer documento que forma parte del expediente de la consulta examinada es el Memorial, sin fecha, remitido al rey Carlos II por Gerónima de Solís, que como sabemos era «poder haviente» en este conflicto de su hermano el conde de Montellano por hallarse ausente cumpliendo sus funciones como virrey de Cerdeña. En el citado Memorial, de contenido similar al de la contradicción ya explicada, planteaba al monarca los peligros que para las casas de su Mayorazgo - las de la calle Concejo- suponían las actuaciones de los religiosos, haciendo referencia a los hechos antes expuestos ${ }^{64}$. Estas actuaciones estimaba la suplicante ser muy perjudiciales para sus casas, precisando que su finalidad última era que quedasen abandonadas. Al no haber convenido la ciudad a la construcción del pasadizo - continuaba exponiendo - los religiosos procedieron a la demolición violenta,

64. En concreto, explicaba que «han pretendido en barias ocasiones se les den las casas principales deste mayorazgo para ensanchar la suya», lo cual no había tenido efecto, pero que «aora nuevamente por caminos extraordinarios y violentos medios quieren minar a lo largo una calle y hazer pasadizo por devajo dellas a otras casas de mayorazgo que compraron», como sabemos las de Lugo (AHN, Consejos, Legajo 7211).

Ediciones Universidad de Salamanca / 요 Stud. his., H. ${ }^{a}$ mod., 41, n. 2 (2019), pp. 275-302 
pero esperaron a que su hermano partiera para Cerdeña para que ella quedase sola y no se opusiera ${ }^{65}$. Por todas las razones expuestas Gerónima de Solís suplicaba al rey que ordenara a los religiosos que cesasen en estas obras hasta el regreso de su hermano ${ }^{66}$.

Enterados los Carmelitas de este Memorial, a su vez remitieron otro al monarca, al que ya nos hemos referido, del que tampoco aparece la fecha, pero sabemos por alusiones que es posterior al anterior. Nos proporciona nuevas noticias y se remonta atrás en el tiempo hablándonos del pleito anterior entre los Carmelitas descalzos y la ciudad de Salamanca y la parroquia de Santo Tomé celebrado en la Audiencia escolástica.

En primer lugar, se exponía la circunstancia sabida de que por la escasez de espacio del colegio se compró una casa inmediata a la del conde de Montellano, pero se añadía: "para hazer ensu suelo nueba planta de iglesia conforme a su instituto» ${ }^{67}$. Hay que resaltar que por primera vez en toda la documentación manejada aparece otro elemento de controversia, la construcción de la nueva iglesia por los Carmelitas, a la que hasta ahora no se había hecho mención. Después continuaban narrando los hechos ya conocidos referidos al desarrollo del litigio ante la Audiencia escolástica, que según las noticias de este Memorial se resolvió favorablemente al colegio, y a la petición de la marquesa de Villaviciosa, denegada, de que se le diese traslado de los autos para poder pedir justicia ante otras instancias.

En segundo lugar, se declaraba en este Memorial por los Carmelitas que habían oído que la citada marquesa había remitido al monarca un Memorial exponiendo los perjuicios que causaba a su casa la construcción de la nueva iglesia, pretendiendo el sobreseimiento de la obra empezada y que esta pendencia se conociera ante el Consejo de Castilla ${ }^{68}$. Nótese que en todo momento las alusiones de los Carmelitas se refieren a la edificación de la nueva iglesia y no a la de las nuevas dependencias del colegio. Los religiosos argumentaban que la suspensión de la construcción de la iglesia provocaría un daño irreparable en la fábrica de la misma «por las continuadas aguas del ibierno", y que el deseo de Gerónima de que se conociese su pretensión ante el Consejo se debía a que no había obtenido respuesta favorable del maestrescuela ${ }^{69}$. Por todo ello suplicaban al monarca que mandase que no se pusiera «embargo ni enbarazo alguno enla obra y fábrica enpezada», y que la marquesa acudiera a la Audiencia escolástica para alegar sus razones en contra y no ante ningún otro tribunal ${ }^{70}$.

65. AHN, Consejos, Legajo 7211.

66. AHN, Consejos, Legajo 7211.

67. AHN, Consejos, Legajo 7211.

68. AHN, Consejos, Legajo 7211.

69. AHN, Consejos, Legajo 7211.

70. AHN, Consejos, Legajo 7211.

Ediciones Universidad de Salamanca / అ@@ Stud. his., H. ${ }^{a}$ mod., 41, n. 2 (2019), pp. 275-302 
Por tanto, se puede pensar que la marquesa quería, además de paralizar las obras, cambiar la jurisdicción ante la que se tenía que sustanciar y dirimir el posible litigo, abandonando el fuero académico por la jurisdicción del Consejo de Castilla, persuadida de los posibles apoyos que pudiera tener su hermano en la Corte, donde no en vano era ya un personaje conocido con contactos e influencias de alto nivel.

El Consejo de Castilla solicitó, como era habitual en estos casos, informes sobre los hechos, y, como en otras tantas ocasiones, se requirieron al corregidor y al obispo de la ciudad. En su informe de 4 de diciembre de 1697, Francisco Gil de Gibaja, que era en esa época corregidor de Salamanca (Villar, 1887: 57), indicaba que remitía un plano con la planta de todos los edificios implicados en esta controversia para que el presidente del Consejo, Antonio de Argüelles y Valdés (Fayard, 1982: 147), pudiera hacerse idea clara de su situación ${ }^{71}$ (es el que hemos incorporado en páginas anteriores). Además, proporcionaba noticias desconocidas sobre el devenir de esta pendencia, sobre todo los intentos para resolverla protagonizados por la ciudad y por Gerónima de Solís. Así, en primer lugar informaba que al tiempo de la denegación de la licencia para excavar el pasadizo, por dictamen de algunos capitulares se les ofreció a los religiosos «todo el terreno que ocupan las cassas que ay desde el combento hasta la plaza», pero despreciaron esta posibilidad ${ }^{72}$. Ofrecimiento del que hasta el momento no hemos encontrado ninguna noticia. Hacía constar igualmente que doña Gerónima pretendió solucionar este problema en previsión de los perjuicios que se iban a producir en sus casas y de la posible pérdida de parte del jardín, puesto que sospechaba que tras esa denegación solicitarían permiso para hacer el paso dentro de este último ${ }^{73}$. Por ello propuso permutar su casa y jardín por las casas de Lugo, a lo que se negaron los religiosos, con la intención, según la marquesa, de pasar por su jardín o de dominar todas las posesiones de esta manzana ${ }^{74}$. $\mathrm{Al}$ igual que en el supuesto anterior también es la primera mención referida a una posible permuta. Nos preguntamos si estas novedades relatadas por el corregidor salmantino obedecen o no a la realidad, puesto que ni se había tenido ni se vuelve a tener constancia de estas actuaciones $u$ ofrecimientos.

El otro informe se remitió también el 4 de diciembre al presidente del Consejo de Castilla por el obispo de Salamanca, Francisco Calderón de la Barca, que estaba en el cargo cuando se construyeron las nuevas dependencias del colegio de San Elías y la iglesia del Carmen, cuya inauguración presidió (Vicente, 1901: 177 y 178). Testigo y participante en la etapa final de la construcción de la catedral nueva salmantina, no resulta sorprendente que encargase su realización a un miembro de la familia

71. AHN, Consejos, Legajo 7211.

72. AHN, Consejos, Legajo 7211.

73. AHN, Consejos, Legajo 7211.

74. AHN, Consejos, Legajo 7211.

Ediciones Universidad de Salamanca / అ@@ Stud. his., H. ${ }^{a}$ mod., 41, n. 2 (2019), pp. 275-302 
Churriguera, a cuyos integrantes posiblemente conocía y había tratado. En concreto, en el informe, de fecha 3 de diciembre de 1697, declaraba José Churriguera que reconocidas las casas del conde era evidente que con las obras se les privaba de luz y que también era cierto que la comunicación entre las dos partes del convento solo era posible minando la calle o tomando un trozo del jardín de las casas del conde de Montellano ${ }^{75}$. Por todo ello realizaba una propuesta para resolver el conflicto, consistente en que los Carmelitas dejasen sin edificar una franja de su espacio «para el desaogo de las casas» y que la marquesa les cediera un pedazo de su jardín para comunicar los dos conventos ${ }^{76}$. Churriguera, por tanto, constataba los hechos y proponía una solución.

Por último, también forma parte del expediente analizado la consulta de 15 de enero de 1698, elevada por iniciativa del Consejo de Castilla al monarca, previa remisión por este de toda la documentación incorporada al citado expediente mediante «real decreto» de 23 de diciembre de 1697. En dicha consulta, en la que informaba al rey de todas su actuaciones, el Consejo hacía constar que de todos los documentos presentados resultaba, por un lado, los perjuicios que se hacían en las casas de la marquesa con las obras del nuevo templo, y por otro, su petición de providencia para su suspensión ${ }^{77}$. En vista de esta situación y teniendo en cuenta que ninguna de las partes había iniciado juicio contencioso, este organismo resolvió requerir al corregidor y a la ciudad de Salamanca ordenando que nombrasen peritos para que realizaran inspección ocular con la finalidad de probar o no la certeza de los hechos, pero además determinó que se paralizasen las obras que estaban acometiendo los Carmelitas $^{78}$. Esta decisión, aunque meramente provisional, era muy favorable a los intereses de Gerónima de Solís, e indirectamente a los de su hermano, futuro presidente del Consejo de Castilla. Parece que fue el 14 de enero - un día antes de la fecha de la consulta - cuando este órgano colegiado había dado provisión ordenando que cesasen las mencionadas obras ${ }^{79}$.

En definitiva, una nueva instancia jurisdiccional, el Consejo de Castilla, a solicitud de una de las partes enfrentadas, se había entrometido en estas controversias, aunque la otra, los Carmelitas descalzos, pensaba que la jurisdicción que tenía que actuar para dirimir las diferencias era la del maestrescuela de la Universidad de Salamanca. En las preferencias de una u otra parte subyacían claramente posibles influencias

75. AHN, Consejos, Legajo 721.

76. AHN, Consejos, Legajo 7211.

77. AHN, Consejos, Legajo 7211.

78. AHN, Consejos, Legajo 7211.

79. Así se afirma en otro documento posterior: «se formó pleito en el Real Consejo y a instancia de los yntheresados se ganó Real provission ${ }^{\text {on }}$ fecha catorze de hener ${ }^{\circ}$ de mill seiscien ${ }^{\text {tos }}$ noventa y ocho cometida al señor corregidor que entonzes fenezía para que hiziese embargo de dicha obra» (LAA de 1702, fol. 23r, en AHMS, RAS 1997/87).

Ediciones Universidad de Salamanca / @®@@ Stud. his., H. ${ }^{a}$ mod., 41, n. 2 (2019), pp. 275-302 
REGINA M. ${ }^{a}$ POLO MARTÍN

CONFLICTOS Y JURISDICCIONES: LA CONSTRUCCIÓN DEL NUEVO EDIFICIO E IGLESIA

DEL CONVENTO Y COLEGIO DE SAN ELÍAS DE SALAMANCA A FINALES DEL SIGLO XVII

favorables a sus causas respectivas según el pleito se desarrollase en un tribunal de la Corte, donde el conde de Montellano tenía contactos en las altas esferas, o ante una jurisdicción especial - el fuero académico-, que se supone defendía los intereses del contendiente sujeto a ella, el colegio de San Elías incorporado al Estudio salmantino.

\subsection{De nuevo el consistorio de Salamanca}

De acuerdo con lo ordenado por el Consejo de Castilla, en la reunión ordinaria del ayuntamiento de 22 de enero de 1698 se nombraron dos capitulares para que, con asistencia del procurador, ejecutasen esa real provisión ${ }^{80}$. Posteriormente, en la del 25 de febrero - a ella acudió el Padre Guardián de San Francisco manifestando su oposición a que prosiguiesen las obras de los Carmelitas ${ }^{81}$ - se debatió y votó sobre las citadas obras, acordándose, a pesar de que hubo posturas en contrario, que se pleitease en Madrid contra los Carmelitas descalzos en defensa del derecho de la ciudad y que se escribiese a la Diputación del Reino sobre esta decisión ${ }^{82}$.

La controversia siguió su curso, y de nuevo en el consistorio extraordinario de 11 de abril se abordó este problema. En su inicio se permitió la entrada del padre rector del Carmen descalzo, quien hizo una declaración en la que se apunta una nueva solución. Después de repetir los hechos ya conocidos sobradamente, y de explicar que queriendo demoler lo que era suyo el Consejo mandó cesar en esas obras, afirmó que nunca fue su intención oponerse a lo dispuesto por este organismo, por lo que se comprometía, para tranquilizar a quienes pensasen que querían disponer de dos conventos, a la demolición del antiguo una vez concluidas las obras del nuevo ${ }^{83}$. A continuación se trató sobre el nuevo desafío de los Carmelitas, que haciendo caso omiso de la orden de paralización del Consejo habían continuado con la demolición de parte de las casas de Lugo ${ }^{84}$. Se acordó nombrar comisario para Madrid para este y otros asuntos ${ }^{85}$, a quien se otorgó poder para pleitear contra los religiosos, haciendo las diligencias necesarias para conseguir que se reedificasen esas casas $^{86}$. No obstante, como veremos a continuación, el Consejo de Castilla pocos

80. LAA de 1698, fol. 15v, en AHMS, RAS 1996/83.

81. En concreto, indicó los inconvenientes que para este convento y las órdenes mendicantes tenía «la nueva fundación de carmelitas descalzos», por lo que suplicaba a la ciudad «que se defienda no prosigan en la obra empeçada... y se diga la proposición cuando llegue el caso» (LAA de 1698, fols. 28v-29r, en AHMS, RAS 1996/83).

82. LAA de 1698, fol. 31v, en AHMS, RAS 1996/83.

83. LAA de 1698, fol. 50v, en AHMS, RAS 1996/83.

84. LAA de 1698, fol. 51r, en AHMS, RAS 1996/83.

85. En concreto, salió el voto de Juan del Águila: «se nombre Comisari para Madrid a las pendençias que constan del acuerdo anterior, y respecto a la demoliçión y contrabençión que a echo el carmen descalço» (LAA de 1698, fol. 52r, en AHMS, RAS 1996/83).

86. LAA de 1698, fols. 52r-52v, en AHMS, RAS 1996/83.

Ediciones Universidad de Salamanca / 요 Stud. his., H. ${ }^{a}$ mod., 41, n. 2 (2019), pp. 275-302 
REGINA M.a POLO MARTÍN

CONFLICTOS Y JURISDICCIONES: LA CONSTRUCCIÓN DEL NUEVO EDIFICIO E IGLESIA

DEL CONVENTO Y COLEGIO DE SAN ELÍAS DE SALAMANCA A FINALES DEL SIGLO XVII

días después emitió una resolución que permitía acabar con los enfrentamientos y desbloquear la situación.

\subsection{Otra vez el Consejo de Castilla}

En efecto, estando así la situación el Consejo de Castilla dictó un Auto de 29 de abril de 1698 en el que se disponía que se levantaba la suspensión de la obra en el supuesto de que los religiosos salmantinos se comprometieran a pasar a habitar el nuevo colegio una vez terminada su construcción dejando de usar el antiguo en el que actualmente vivían, debiendo asegurar esta obligación con una fianza de diez mil ducados de vellón ${ }^{87}$. Por tanto, el Consejo puso fin a este litigio permitiendo la continuación de las obras a los Carmelitas siempre que cumplieran lo dispuesto en este Auto, que era lo que el rector había propuesto a iniciativa propia en el consistorio del 11 de abril, dejando a las partes libertad para que acudiesen a las instancias que les pareciera oportuno para defender su derecho.

\subsection{Una vez más el ayuntamiento de Salamanca}

Después del Auto del Consejo todo indica que las obras del convento continuaron, y así lo corroboran algunas noticias halladas en las actas capitulares. En concreto, siendo corregidor de la ciudad Francisco Antonio de Salcedo Aguirre (Villar, 1887: 57), en el consistorio ordinario de 2 de diciembre de 1699 se acordó que los sobrefieles, junto al teniente del corregidor, reconociesen el daño ocasionado a las murallas «con la tierra dela obra delos carmelitas que han echado junto a ella y pongan remedio para que no tenga menoscabo alguno dicha muralla ${ }^{88}$, de lo que se desprende que proseguían las obras. Casi dos años después, en la reunión capitular ordinaria del 14 de octubre de 1701, el colegio de Carmelitas pedía al consistorio licencia para ocupar parte de la plazuela de Santo Tomé para colocar unas gradas en la entrada del nuevo colegio ${ }^{89}$. Del lenguaje utilizado y de la petición se deduce que las obras de los nuevos convento e iglesia estaban ya prácticamente terminadas, pues se estaba habilitando la entrada. La ciudad acordó que, en contra de la costumbre inmemorial de no otorgar las súplicas sin previo informe de los comisarios, en este supuesto, atendiendo a los beneficios de que la ciudad era deudora a Santa Teresa y

87. Este Auto aparece transcrito en el consistorio de 4 de marzo de 1702 (LAA de 1702, fol. 27r, en AHMS, RAS 1997/87).

88. LAA de 1699, fol. 165v, en AHMS, RAS 1996/84.

89. En concreto, solicitaban: «nos conçeda su lizencia y veneplácito para tomar seis pies de sitios en la Plaçuela de Santo Tome donde caen las puertas de la Yglesia nueva que an echo y en otro sitio poner unas gradas que sirban para entrar en la Portería del nuevo Colegio que an edificado» (LAA de 1701, fol. 226r, en AHMS, RAS 1997/86).

Ediciones Universidad de Salamanca / @®@@ Stud. his., H. ${ }^{a}$ mod., 41, n. 2 (2019), pp. 275-302 
a los favores recibidos de los religiosos, se concedieran esos «seis pies» de terreno requerido ${ }^{90}$. Por tanto, parece que el ayuntamiento salmantino en poco tiempo había pasado de oponerse con vehemencia a las obras de los Carmelitas a apoyar sin fisuras su culminación.

Sin embargo, los antiguos contendientes volvieron a enfrentarse, ya que en el consistorio ordinario de 1 de febrero de 1702 los Carmelitas, tozudos, retornaron a su antigua petición de la construcción del pasadizo. Ejercía ya como corregidor de la ciudad Rodrigo Antonio Falcón de Ulloa, marqués de Bendaña ${ }^{91}$. En concreto, el rector del colegio, Juan de la Madre de Dios, informaba en esa reunión que, como era notorio, se había construido ya el nuevo colegio, siendo por consiguiente distinta la situación a la del momento en que se hizo por primera vez esta solicitud. También explicaba que todavía estaban los religiosos en la vivienda antigua, a pesar de ser inhabitable por estar ruinosa, llena de goteras y faltar espacio «de piezas mui prezisas como aula, libreria, y otras ofizinas inescusables» ${ }^{92}$. Por todo ello afirmaba que era muy necesaria la comunicación entre la nueva vivienda y la antigua, informando que, a pesar de haber intentado de nuevo la compra de la casa del conde de Montellano, o de parte del jardín o corral, no se había conseguido, de manera que la única solución sería construir «un pasadizo sotterraneo» por debajo de la calle de Cabrera ${ }^{93}$, pidiendo otra vez que se le otorgase la correspondiente licencia para esta obra ${ }^{94}$. En esta reunión se acordaron varias medidas: en primer lugar, que para determinar los posibles perjuicios para el bien público o particular de las casas adyacentes se tenía que reconocer el sitio «por maestros experimentados» elegidos por los comisarios nombrados para tratar este tema; y en segundo lugar, respecto al perjuicio de los particulares, que los religiosos debían hacer las pertinentes diligencias con los propietarios de las casas inmediatas al pretendido pasadizo, citando especialmente al conde de Montellano, a Enrique Enríquez en nombre de su padre el conde de Canillas y a Francisco Ordóñez Flores ${ }^{95}$.

En el consistorio ordinario de 4 de marzo de ese mismo año se volvió a tratar del asunto. En primer lugar se leyeron las peticiones de cada una de las personas antes mencionadas, en las que los argumentos que esgrimieron para rebatir otra

90. LAA de 1701, fol. 226r, en AHMS, RAS 1997/86.

91. LAA de 1701, fols. 139r-140r, en AHMS, RAS 1997/86.

92. LAA de 1702, fol. 11v, en AHMS, RAS 1997/87.

93. Agregaba que no resultaría perjuicio público a la calle «por ser un cañón soterraneo solo de zinco pies de hancho sobre la peña viva que es menester hazer a pico, y con arco mui fuerte», ni a las casas colindantes, puesto que dicha calle tenía quince pies de anchura y al ocupar el «cañón» cinco quedarían otros cinco para cada lado (LAA de 1702, fol. 11v, en AHMS, RAS 1997/87).

94. LAA de 1702, fols. 11r-12r, en AHMS, RAS 1997/87.

95. LAA de 1702, fol. 12r, en AHMS, RAS 1997/87. 
vez la construcción del pasadizo eran básicamente el acuerdo del consistorio de 22 de agosto de 1696 denegatorio de otra solicitud semejante de licencia y el Auto del Consejo de 29 de abril de 1698 que ordenaba que, una vez acabadas las obras, los religiosos tenían que pasar a residir en el convento nuevo abandonando el antiguo, por lo que ya no sería necesario comunicarlos, estimando que no habiéndose producido cambios la corporación debía denegar de nuevo esa pretensión de unirlos por un paso subterráneo ${ }^{96}$.

Y eso fue lo que acordó el ayuntamiento salmantino, teniendo en cuenta los mencionados acuerdo consistorial y Auto del Consejo y los pareceres «uniformes» emitidos en su momento por los abogados Andrés García Samaniego y Lorenzo González, y persuadidos de que los Carmelitas tenían la intención de mantener los dos colegios en contravención de lo dispuesto en el citado Auto ${ }^{97}$. Por tanto, parece que la corporación quiso zanjar de una vez por todas este problema.

No obstante, no se vieron cumplidos sus deseos porque tenemos noticia de que en la reunión de 23 de junio de 1702 se notificaron a la ciudad dos autos proveídos por el corregidor en el nuevo pleito que los Carmelitas habían iniciado sobre su pretensión de abrir el pasadizo ${ }^{98}$. Los dos Autos citados eran de 12 y 22 de mayo de 1702, y por ellos se mandaba dar traslado de los hechos a los interesados en el pleito, y la ciudad de Salamanca lo era. Los capitulares reunidos pasaron a conferenciar acerca de lo que se debía hacer, y a votar, acordando comisionar al procurador general para que defendiese a la ciudad y al bien común en el litigio, y pidiendo que se cumpliera el Auto del Consejo de Castilla de 29 de abril de 1698 y se ejecutaren debidamente los acuerdos del consistorio de 22 de agosto de 1696 y de 4 de marzo de $1702^{99}$.

\section{CONCLUSIONES}

Advertimos que no se ha conservado el Libro de Actas del Ayuntamiento salmantino de 1703 por lo que no es posible rastrear lo acaecido respeto a esta cuestión en este año, que fue en el que se inauguró la nueva iglesia. Tampoco se encuentra noticia alguna en el de 1704, casi dedicados los consistorios en su integridad a abordar problemas derivados de las operaciones militares de la Guerra de Sucesión. En cualquier caso, sabemos que cuando el colegio, por fin, compró las casas del duque de Montellano en 1764 todavía estaban incomunicados los dos espacios del convento (López y Rupérez, 1992-1993: 161 y García, 20 I 5: 427, nota

96. LAA de 1702, fols. 23v-26r en AHMS, RAS 1997/87.

97. LAA de 1702, fol. 26v en AHMS, RAS 1997/87.

98. LAA de 1702, fol. 89r en AHMS, RAS 1997/87.

99. LAA de 1702, fols. 89v-90r en AHMS, RAS 1997/87.

Ediciones Universidad de Salamanca / అ@@ Stud. his., H. ${ }^{a}$ mod., 41, n. 2 (2019), pp. 275-302 
223), por lo que no habían conseguido su pretensión. A partir de este momento, tal y como se refleja en un plano de la zona del año de 1798 obra de Jerónimo García de Quiñones, el convento de San Elías ocupaba ya toda la manzana, delimitada por las calles de Cabrera, Peripacho, Concejo y por la plazuela de Santo Tomé (García, $2015: 428$, fig. 103). El Gobierno, que con la desamortización había incautado el colegio con todos sus anexos, vendió en 1839 el edificio conventual al segundo marqués de Benalúa (García, 20 I 5: 429). En años posteriores fue demolido casi en su totalidad, construyéndose, ocupando parte de la huerta del convento, la actual plaza de la Libertad (García, 20 I 5: 429).

El análisis de estos hechos sirve para mostrar la elevada conflictividad existente en la sociedad de la época de los Austrias, que desembocó en la constante celebración de litigios en los que intervenían, incluso se superponían, distintas instancias judiciales en función de las circunstancias o de los intereses particulares de los litigantes. Esta situación era muy llamativa en el caso de Salamanca, debido a que además de la justicia regia, la municipal y la del obispo, que eran las habituales en las principales ciudades, existía la Audiencia escolástica de la universidad. Estas pendencias judiciales se dilataban mucho en el tiempo, ocasionando gastos muy gravosos para las partes y una elevada inseguridad jurídica, y además en ocasiones se complicaban hasta extremos insospechados por los conflictos de competencia jurisdiccional que a menudo se suscitaban.

El pleito analizado es buena muestra de esta complejidad. Intervienen como partes implicadas una institución eclesiástica, el convento y colegio de San Elías de los Carmelitas descalzos acogido al fuero universitario; otra de carácter municipal, el ayuntamiento salmantino, que además de ser el responsable merced a sus competencias gubernativas de conceder las licencias urbanísticas, litiga en defensa de los intereses de la ciudad como parte en los pleitos que se siguen; y los particulares afectados, todos ellos integrantes de los grupos de la oligarquía ciudadana, incluso algunos de ellos con cargos importantes en el gobierno de la Monarquía. Las instancias judiciales que conocieron de estas controversias son la Audiencia escolástica salmantina, que decide a favor del colegio acogido a su jurisdicción, y el Consejo de Castilla, que parece que se inclina por las pretensiones de una de las partes con excelentes contactos en la Corte. Por tanto, una jurisdicción especial y la justicia regia se vieron implicados en esta controversia. En todo caso, aunque el Consejo adopta una solución de compromiso, estimo que tratando de dar satisfacción a los intereses de todos los afectados, el convento Carmelita, contumaz en sus pretensiones, no la cumplió, lo que a la postre originó nuevos pleitos, aunque no pudo conseguir su propósito hasta bien avanzado el siglo XVIII y por otra vía diferente a la judicial. 
REGINA M. ${ }^{a}$ POLO MARTÍN

CONFLICTOS Y JURISDICCIONES: LA CONSTRUCCIÓN DEL NUEVO EDIFICIO E IGLESIA

DEL CONVENTO Y COLEGIO DE SAN ELÍAS DE SALAMANCA A FINALES DEL SIGLO XVII

\section{REFERENCIAS BIBLIOGRÁFICAS}

ALONSO ROMERO, P. (1997). Universidad y sociedad corporativa. Historia del privilegio jurisdiccional del Estudio salmantino. Madrid: Tecnos.

ALONSO ROMERO, P. (2004). El Fuero universitario salmantino, siglos XIII-XIX. En, L. E. Rodríguez-San Pedro Bezares (coord.), Historia de la Universidad de Salamanca. Vol. II, Estructuras y flujo. Salamanca: Ediciones Universidad de Salamanca, 161-188.

ANGUITA CANTERO, R. (1997). Ordenanza y Policía urbana. Los orígenes de la reglamentación edificatoria en España (1750-1900). Granada: Universidad de Granada.

BARRIOS PINTADO, F. (1984). El Consejo de Estado de la Monarquía absoluta, 15211812. Madrid: Consejo de Estado.

BARRIOS PINTADO, F. (2015). La Gobernación de la Monarquía de España. Consejos, Juntas y secretarios de la administración de Corte (1556-1700). Madrid: Boletín Oficial del Estado.

BLASCO ESQUIVIAS, B. (1991). Teodoro Ardemans y su entorno en el cambio de siglo (1661-1726). Aspectos de la arquitectura y el urbanismo madrileños de Felipe II a Carlos III. Tesis doctoral, 2 volúmenes. Madrid: Universidad Complutense de Madrid.

BONET CORREA, A. (1978). Morfología y ciudad. Urbanismo y arquitectura durante el Antiguo Régimen en España. Barcelona: Gustavo Gili, D. L.

BONET CORREA, A. (1991). El urbanismo en España e Hispanoamérica. Madrid: Cátedra, D. L.

CASTRO, C. de. (2004). A la sombra de Felipe V. José de Grimaldo, ministro responsable (1703-1726). Madrid: Marcial Pons Historia.

DIOS, S. de. (1982). El Consejo Real de Castilla (1385-1522). Madrid: Centro de Estudios Constitucionales.

DIOS, S. de. (1986). Fuentes para el estudio del Consejo Real de Castilla. Salamanca: Diputación de Salamanca.

DUBET, A. (2008). Un estadista francés en la España de los Borbones. Juan Orry y las primeras reformas de Felipe V(1701-1706). Madrid. Biblioteca Nueva, D. L.

FAYARD, J. (1982). Los miembros del Consejo de Castilla (1621-1746). Madrid: Siglo veintiuno de España editores.

GARCÍA CATALÁN, E. (2015). Urbanismo de Salamanca en el siglo XIX. Salamanca: Ediciones Universidad de Salamanca, D. L.

GARMA Y DURÁN, F. X. de. (1751). Theatro Universal de España, descripción Eclesiástica, y Secular de todos sus Reynos, y Provincias en General, y Particular, Tomo Quarto. Barcelona: Imprenta de Mauro Marti.

GONZÁlEZ ALONSO, B. (1988). La Justicia. En M. Artola (dir.), Enciclopedia de Historia de España, vol. 2. Madrid: Alianza, 343-420.

GRANDA, S. (2013). La presidencia del Consejo Real de Castilla. Madrid: Centro de Estudios Políticos y Constitucionales.

Ediciones Universidad de Salamanca / అ@@ Stud. his., H. ${ }^{a}$ mod., 41, n. 2 (2019), pp. 275-302 
REGINA M. ${ }^{a}$ POLO MARTÍN

CONFLICTOS Y JURISDICCIONES: LA CONSTRUCCIÓN DEL NUEVO EDIFICIO E IGLESIA

DEL CONVENTO Y COLEGIO DE SAN ELÍAS DE SALAMANCA A FINALES DEL SIGLO XVII

LÓPEZ BENITO, C. I. y RUPÉREZ ALMAJANO, M. ${ }^{a}$ N. (1992-1993). Aportación al estudio de la nobleza salmantina en la Edad Moderna a través de sus casas. Studia Historica. Historia Moderna, X-XI, 149-168.

LÓPEZ BENITO, C. I. (1997). La sociedad salmantina de la Edad Moderna. En J. L. Martín (coord.), Historia de Salamanca, vol. III, A. Rodríguez (dir.), Historia Moderna. Salamanca: Centro de Estudios Salmantinos, 95-371.

LOZANO BARTOLOZZI, M. ${ }^{a}$ M. (2011). Historia del urbanismo en España. II, Siglos XVI, XVII y XVIII. Madrid: Cátedra.

LLAMAS MARTÍNEZ, E. (2002). El Colegio de San Elías y los Salmanticenses. En E. Rodríguez-San Pedro Bezares (coord.), Historia de la Universidad de Salamanca. Vol. I, Trayectoria histórica e Instituciones vinculadas. Salamanca: Ediciones Universidad de Salamanca, 687-704.

MADRUGA REAL, Á. (2005). Las plazas en torno a la Plaza Mayor de Salamanca. Espacios urbanos del medievo al siglo XX. Salamanca: D. L. Globalia Artes Gráficas.

MARTÍNEZ FRÍAS, J. M., PÉREZ HERNÁNDEZ, M. y LAHOZ, L. (2008). El Arte barroco en Salamanca. Salamanca: Gruposa, S.A. La Gaceta Regional, D. L.

MONTANER LÓPEZ, E. (1987). Aportaciones a la Historia del urbanismo: Salamanca en el siglo XVII. Salamanca. Revista de Estudios, 24-25, 9-28.

MUÑOZ JIMÉNEZ, J. M. (1990). Arquitectura carmelita. Ávila: Comisión Provincial del Cuarto Centenario de la muerte de San Juan de la Cruz.

NIETO GONZÁLEZ, J. y RUPÉREZ ALMAJANO, M. ${ }^{a}$ N. (1998). Trazado visual y limitaciones de la política urbana a finales del Antiguo Régimen: Un caso de Salamanca. Espacio, Tiempo y Forma. Serie VII, Historia del arte, 11, 343-366.

ORTIZ DE ZÚÑIGA, D. (1796). Anales Eclesiásticos y Seculares de la muy Noble y muy Leal Ciudad de Sevilla, Metrópoli de la Andalucía, Tomo V. Madrid: Imprenta Real.

RUPÉREZ ALMAJANO, M. ${ }^{a}$ N. (1992). Urbanismo de Salamanca en el siglo XVIII. Salamanca: Colegio Oficial de Arquitectos de León.

SÁNCHEZ VAQUERO, J. (2011). Linajes de Salamanca. Salamanca: Publicaciones Universidad Pontificia.

SANTA MARÍA, Frai F. de. (1644). Reforma de los Descalzos de Nuestra Señora del Carmen de la primitiva Observancia. Madrid: Por Diego Diaz de la Carrera.

VICENTE BAJO, J. A. (1901). Episcologio salmantino desde la antigüedad hasta nuestros dias. Salamanca: Imprenta de Calatrava.

VILLAR Y MACÍAS, M. (1887). Historia de Salamanca, tomo III. Salamanca: Imprenta de Francisco Núñez Izquierdo.

Ediciones Universidad de Salamanca / అ@@ Stud. his., H. ${ }^{a}$ mod., 41, n. 2 (2019), pp. 275-302 